\title{
Políticas de expansão da educação superior no Brasil 1995-2010
}

\author{
DEISE MANCEBO \\ Universidade do Estado do Rio de \\ Janeiro, Rio de Janeiro, RJ, Brasil \\ ANDRÉA ARAUJO DO VALE \\ Universidade Federal Fluminense, \\ Niterói, RJ, Brasil \\ TÂNIA BARBOSA MARTINS \\ Universidade Metodista de Piracicaba, \\ Piracicaba, SP, Brasil
}

\section{RESUMO}

O artigo apresenta as principais tendências da expansão da educação superior no Brasil, entre 1995 e 2010, com base em quatro eixos. Primeiramente, expõe o progressivo quadro de privatização, tanto no que se refere ao crescimento das instituições privado-mercantis como à mercantilização das instituições públicas. Apresenta, em seguida, a expansão promovida pelo governo federal, analisando particularmente o Programa de Apoio a Planos de Reestruturação e Expansão das Universidades Federais (REUNI). Discute, como terceira tendência, o quadro de expansão do ensino a distância e, por fim, debate o crescimento da pós-graduação com a redefinição de seus rumos no sentido do empresariamento do conhecimento. Conclui que, em todos esses campos, foram induzidas alterações substantivas, sob a regência de um ideário que apela à economia de mercado, racionaliza os gastos públicos com base em um sistema de parceria entre Estado e mercado e suprime diversos direitos e conquistas sociais transmutados em serviços, regidos por um intenso processo de mercantilização.

\section{PALAVRAS-CHAVE}

expansão da educação superior; privatização; REUNI; ensino a distância; empresariamento do conhecimento. 


\title{
EXPANSION OF HIGHER EDUCATION POLICY IN BRAZIL: 1995-2010
}

\begin{abstract}
The paper presents the main trends of the expansion of higher education in Brazil, between 1995 and 2010, based in four areas. First, it exposes the progressive privatization, both in respect of the growth of private-market institutions and the commodification of public institutions. Then, it displays the expansion promoted by the federal government, particularly analyzing the Support Program for the Restructuring and Expansion of Federal Universities (REUNI). As a third trend, the expansion of distance learning and, finally, the growth of post graduation, redefining entrepreneurial knowledge. The conclusion is that, in all these fields, substantive changes were induced, under the ideology that appeals to a market economy, rationalizing public spending, based on a system of partnership between state and market, and suppressing various rights and social achievements, transmuted into services, governed by an intense process of mercantilization.
\end{abstract}

\section{KEYWORDS}

expansion of higher education; privatization; REUNI; distance learning; entrepreneurship knowledge.

\section{POLITICAS DE EXPANSIÓN DE LA EDUCACIÓN SUPERIOR EN BRASIL: 1995-2010}

\section{RESUMEN}

El artículo presenta las principales tendencias de la expansión de la educación superior en Brasil, entre 1995 y 2010, a partir de cuatro ejes. En primer lugar, se expone el cuadro de la progresiva privatización, tanto en lo que respecta al crecimiento de las instituciones privadas, como a la mercantilización de las instituciones públicas. Se presenta, enseguida, la expansión promovida por el gobierno federal, analizando, en particular, el Programa de Apoyo al Plan de Reestructuración y Expansión de las Universidades Federales (REUNI). Se discute, como tercera tendencia, el cuadro de la expansión de la enseñanza a distancia y, finalmente, se debate el crecimiento de posgrado, con la redefinición de sus rumbos hacia la producción de conocimiento direccionado a las empresas. Se concluye que, en todos estos campos, cambios sustanciales fueron inducidos, bajo la regencia de un ideario que apela a una economía de mercado, racionaliza el gasto público basado en un sistema de asociación entre el Estado y el mercado y suprime varios derechos y conquistas sociales transmutados en servicios, que se rigen por un intenso proceso de mercantilización.

\section{PALABRAS CLAVE}

expansión de la educación superior; privatización; REUNI; educación a distancia; empresariamiento del conocimiento. 
Indiscutivelmente, a educação superior passa por amplos processos de mudança nos últimos vinte anos, e praticamente em todo o mundo. As reformas, onde ocorreram, invariavelmente remeteram à necessidade de expansão do sistema, o que de fato tem ocorrido, mesmo que a intensidade seja variável entre os países.

Se, por um lado, a expansão engendrada nas últimas décadas pode ser percebida como positiva por ampliar o acesso da população ao ensino superior, deve-se atentar para alguns efeitos perversos desse mesmo processo, particularmente no que tange ao perfil dos cursos e das carreiras criados pelas instituições privadas, cuja expansão se dá sob a influência direta de demandas mercadológicas, valendo-se dos interesses da burguesia desse setor em ampliar a valorização de seu capital com a venda de serviços educacionais.

A produção de conhecimento também cresceu no país, fruto direto da expansão da pós-graduação, embora se apresente, cada vez mais, atrelada à tecnologia e à inovação, imprescindíveis para que o capitalismo possa renovar-se e ampliar sua margem de riqueza tendo como princípio a base industrial consolidada.

O importante é ressaltar que o crescimento do ensino superior privado, a produção de conhecimento atrelado à inovação, mesmo que advindo de instituições públicas, e, em algumas circunstâncias, a própria expansão do ensino na rede pública são facetas de um movimento de expansão que traduzem, de forma crescente, o modo como o capital busca valorizar-se no âmbito dos sistemas de educação superior.

Munidas dessas preocupações, pretendemos discutir neste texto as principais tendências da recente expansão da educação superior no Brasil. ${ }^{1}$ É um tema complexo, que aqui será abordado, num esforço de síntese, com base em quatro grandes eixos: (1) o expressivo aumento das instituições de ensino superior (IES) com fins lucrativos, isto é, privados/mercantis; (2) algumas ações do governo federal expandindo vagas, matrículas e cursos nas instituições federais de ensino superior (IFES), seja pela multiplicação dos campi das IFES já existentes, pela expansão do número de instituições, ou, ainda, mediante programas de reestruturação do setor, como é o caso do Programa de Apoio a Planos de Reestruturação e Expansão das Universidades Federais (REUNI); (3) a forte diferenciação de cursos, instituições e modalidades de ensino de graduação, cabendo destaque à utilização do ensino a distância (EaD); e (4) a expansão da pós-graduação, com redefinição de seus rumos no sentido do empresariamento do conhecimento.

O período tomado para a análise inicia-se em 1995 - ano da Reforma Administrativa do Estado brasileiro, que, segundo Paulani (2008, p. 110), corresponde ao "estágio em que o mercado seria o comandante indisputado de todas as instâncias do processo de reprodução material da sociedade" - e cobre a gestão dos

1 Os dados e análises aqui apresentados são resultado da pesquisa integrada Politicas de expansão da educação superior no Brasil, coordenada pela professora Deise Mancebo, desenvolvida por pesquisadores brasileiros pertencentes à Rede Universitas/Br e à Associação Nacional de Pós-Graduação e Pesquisa em Educação (ANPEd). Ela é financiada pela Fundação de Apoio à Pesquisa do Estado do Rio de Janeiro (FAPERJ), pelo Conselho Nacional de Desenvolvimento Científico e Tecnológico (CNPq) e pela Coordenação de Aperfeiçoamento de Pessoal de Nível Superior (CAPES). 
últimos dois presidentes brasileiros: Fernando Henrique Cardoso (1995-2002) e Luiz Inácio Lula da Silva (2003-2010).

\section{QUADRO GERAL DA EXPANSÃO DA EDUCAÇÃO SUPERIOR NO BRASIL: A DUPLA PRIVATIZAÇÃO DO SISTEMA}

Uma das grandes marcas da educação brasileira, de 1995 aos dias atuais, refere-se ao inegável processo de expansão pelo qual vem passando. Se tomarmos os dados referentes às matrículas, por exemplo, temos a seguinte situação: entre 1995 e 2010, ocorreu um crescimento no número total de matrículas (presenciais e a distância), que passou de 1.759.703, em 1995, para 6.379.299, em 2010, com um crescimento, portanto, da ordem de $262,52 \%$ no espaço de tempo de dezesseis anos. ${ }^{2}$

O traço mais marcante dessa complexa expansão da educação superior brasileira é a "proeminência cada vez maior do mercado educacional, de sua questionável regulação" (Sguissardi, 2008, p. 994). Na realidade, em um contexto internacional marcado pela mundialização econômica e pelas políticas neoliberais, pode-se detectar dois movimentos interligados, que apontam para a privatização da educação superior, acarretando graves consequências para a formação superior, para a produção do conhecimento e da cultura e para o trabalho docente.

Em primeiro lugar, ocorre mundialmente um crescimento desmedido e praticamente sem controle da oferta privada desse tipo de ensino. Informes apresentados na Conferência Mundial sobre Educação Superior, promovida pela Organização das Nações Unidas para a Educação, a Ciência e a Cultura (UNESCO), ocorrida em julho de 2009, em Paris, mostraram claramente o crescimento explosivo da oferta privada, que já detém $30 \%$ da matrícula mundial no ensino superior. Mais da metade da população estudantil do México e do Chile, por exemplo, já recebe educação nessas instituições, cujo ânimo é o lucro. No Brasil, o percentual de matrículas na rede privada não para de crescer, alcançando em 2010, conforme dados do último Censo, um patamar superior a 74,2\% (Mancebo, 2013).

Dados do Sistema de Información de Tendencias Educativas en América Latina, (SITEAL, 2011) também são alarmantes, particularmente para o Brasil. No levantamento realizado sobre a distribuição dos estudantes de nível superior, segundo a natureza administrativa do estabelecimento, em áreas urbanas da América Latina, no ano de 2009, abrangendo quinze países, foi encontrado como resultado uma média de $52 \%$ dos estudantes latinos em instituições privadas. Nesse ranking nada animador, o Brasil, com $77 \%$ de inversão privada, só perde para o Chile, cujo Estado, desde inícios da década de 1980, não oferece mais educação superior pública, o que tem dado vazão, inclusive, a intensos movimentos de protesto, da parte de amplos segmentos daquela sociedade, em defesa da educação pública.

O segundo sentido da privatização pode ser localizado na própria rede pública. Em direta relação com a insuficiência de financiamentos, muitos docentes - em

2 Todos os dados estatísticos apresentados neste texto foram retirados de Brasil. MEC. INEP (2011). 
especial, docentes-pesquisadores - passam a participar do processo de captação de recursos para a pesquisa, para a instituição e até para si, gerando, em algumas situações, contratos com empresas privadas, que promovem o financiamento privado de instalações e investigações orientadas para o mercado, além do estabelecimento de sistemas de patentes sobre resultados científicos logrados e a transferência de tecnologia das universidades para empresas (Mancebo, 2013).

Assim, é crescente o número de investigações feitas na universidade pública que se referem, diretamente, à produção de ciência, tecnologia e inovações tecnológicas imprescindíveis para que o capitalismo possa renovar-se e ampliar sua margem de lucros (Pochmann, 2008). Pode-se dizer, mesmo, que as universidades públicas ocupam cada vez um papel mais destacado no processo de produção de conhecimento-mercadoria, isto é, aquele que, tornando-se tecnologia e inovação tecnológica, agrega maior valor aos produtos consumidos no mercado interno ou para exportação.

Merece registro que a expansão da educação superior no Brasil, bem como seus dois movimentos de privatização, aparecem diretamente relacionados a dois outros movimentos de acomodação do capitalismo brasileiro, aqui citados tão somente para elucidar a base teórica de onde se parte.

Primeiramente, a expansão da educação superior (e sua privatização) ocorre no mesmo diapasão e para o atendimento das mudanças contemporâneas ocorridas na produção e valoração do capital, a reestruturação produtiva, que teve seu início sistematizado, no Brasil, a partir da década de 1980, e, em segundo lugar, toma impulso e ganha organicidade a partir da reforma gerencialista do Estado brasileiro, posta em movimento em 1995, pelo então ministro da Reforma do Estado Bresser-Pereira, e em curso até os dias atuais.

A partir desses vetores, puderam ser verificadas profundas modificações na cultura e no cotidiano das instituições, nas relações entre o Estado e as instituições públicas e privadas, mas, sobretudo, na formação ministrada nas diversas IES e no trabalho do professor e do pesquisador desse nível de ensino. Especificamente, a Reforma de Estado elaborada no âmbito do Ministério da Administração Federal e Reforma do Estado (MARE) durante o governo de Fernando Henrique Cardoso, embora não tenha sido integralmente aplicada quando da sua formulação, definiu uma racionalidade que penetrou profundamente o coração do Estado no que diz respeito à sua estrutura, atuação, elaboração, implementação e avaliação de políticas públicas em todos os campos, inclusive na educação superior.

\section{O CRESCIMENTO DO MERCADO EDUCACIONAL}

Como já exposto, entre 1995 e 2010, ocorreu no Brasil um crescimento no número total de matrículas da ordem de 262,52\%. Todavia, indiscutivelmente, o que mais se expandiu no período foram as matrículas nas instituições privadas, que tiveram um crescimento da ordem de $347,15 \%$, enquanto na rede pública o aumento foi apenas de $134,58 \%$.

A evolução das matrículas pode ser observada no Gráfico 1 e nos permite algumas análises. 
Gráfico 1 - Evolução das matrículas dos cursos de graduação presenciais e a distância no Brasil, por organização acadêmica (1995-2010)

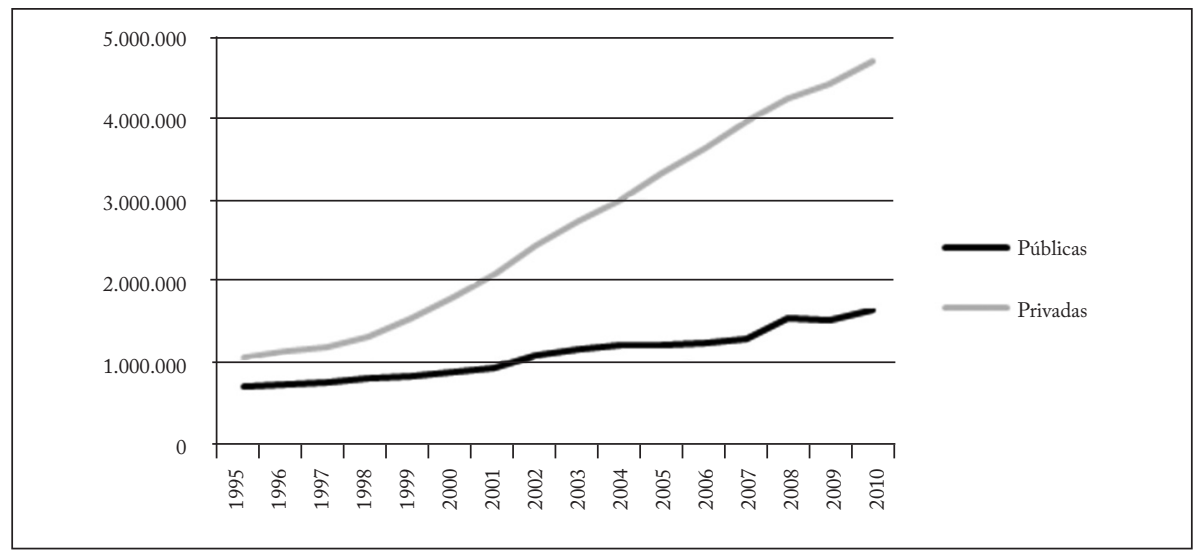

Fonte: Brasil; MEC; INEP (2011).

Elaboração das autoras.

Em 1995, início do primeiro mandato do presidente Fernando Henrique Cardoso, registrava-se a oferta de 39,8\% das matrículas de educação superior em instituições públicas e $60,2 \%$ nas privadas. Em 2002, no final de seu mandato, a tendência privatizante intensifica-se, com 30,8\% das matrículas em instituições públicas para $69,2 \%$ nas privadas. Em 2010, no final do segundo governo do presidente Lula da Silva, o crescimento da rede privada permaneceu como tendência, chegando-se a $25,8 \%$ de matrículas nas IES públicas e 74,2\% nas privadas.

É bem verdade que o crescimento do setor privado sobre o público advém dos tempos da ditadura civil-militar (1964-1984). A situação política daquele período requereu ajustes na educação superior, o que foi feito pela reforma universitária instituída pela lei n. 5.540, de 28 de novembro de 1968. Essa legislação reforçou a atuação do então Conselho Federal de Educação (CFE), com forte composição privatista, e as facilidades, os incentivos fiscais e tributários para a abertura de IES privadas foram incessantemente criados e recriados. Fato é que, ao final da ditadura, as matrículas privadas já ultrapassavam em muito as oferecidas nas IES públicas.

Sempre é bom lembrar que o critério para o oferecimento de cursos nas instituições privadas são suas planilhas financeiras. Isso faz com que haja uma enorme quantidade de cursos de forte apelo mercantil oferecidos nas regiões mais ricas do país e que dão pouquíssimas contribuições para o desenvolvimento econômico, social e cultural do país ou da própria região, ao mesmo tempo em que locais e áreas profissionais que mais necessitam de reforços são abandonados. O critério financeiro atinge, também, a qualidade dos cursos oferecidos, restringindo as possibilidades profissionais dos estudantes e a contribuição que essas IES poderiam dar para o desenvolvimento das diferentes áreas de conhecimento (Helene, 2011).

A despeito desse quadro, governos municipais, estaduais e especialmente a União continuam oferecendo inúmeros subsídios e facilidades ao ensino privado, 
especialmente sob a forma de isenções de impostos e financiamento estudantil, como são os casos do Fundo de Financiamento Estudantil (FIES) ${ }^{3}$ e do Programa Universidade para Todos (PROUNI), ${ }^{4}$ cujo número de bolsas aumenta a cada ano.

O lobby privatista é poderoso e organizado. Faz-se representar no Conselho Nacional de Educação (CNE), e, graças a um sistema político dominado pelos interesses do capital, inclusive por meio do controle do financiamento eleitoral, o setor privatista é majoritário no Congresso Nacional, onde não se envergonha de apresentar propostas que respondem apenas aos interesses mercantis das instituições que representam $(i d e m)$.

Se o sentido da privatização é o mesmo desde o período da ditadura civil- militar - como expusemos, o tratamento da educação como mercadoria a ser comprada pelos usuários desse serviço -, existem fenômenos novos no período que agora tomamos para estudo, dignos de registro. Pelo menos desde meados dos anos 1990, mais precisamente a partir da Reforma Administrativa do Estado Brasileiro (1995), a promiscuidade entre o público e o privado assume novas e variadas formas, que permanecem em curso, como o já citado PROUNI.

Outra tendência a se considerar no período em estudo quanto ao fortalecimento da iniciativa privada envolve a organização de grandes conglomerados, $o$ que significa que o setor tem se consolidado em uma economia de escala, em que grandes grupos oferecem ensino superior barato, com uma qualidade sofrível, uso ampliado de $\mathrm{EaD}$ etc. Esses grandes grupos, muito bons na área de gestão, compram instituições que estão baratas, endividadas, que possuem baixo nível de governança gerencial e muitos passivos. Via administração inteligente, a organização compradora diminui as dívidas e os riscos, até reverter a situação e a empresa voltar a apresentar resultados positivos e lucro.

Por fim, é próprio ao período em estudo a financeirização e internacionalização do setor. No Brasil, há cobertura legal para "a presença de grandes fundos de investimento no chamado mercado educacional [...], como já ocorre em alguns outros países do centro e da periferia global” (Sguissardi, 2008, p. 1.003). Nos anos recentes, também apareceram "diversas firmas de consultoria especializadas em preparar as IES para serem incorporadas por organizações nacionais ou internacionais" (idem, p. 1.005), o que de fato tem ocorrido. Pelo menos quatro grandes grupos - Anhanguera, Estácio de Sá, Sistema Educacional Brasileiro (SEB, Ribeirão Preto/SP) e Kroton (dona da marca Pitágoras) - já abriram seu capital e passaram

3 O FIES, proposto originalmente pela medida provisória n. 1.865-4, de 1999, é um programa do Ministério da Educação (MEC) destinado a financiar prioritariamente estudantes de cursos de graduação matriculados em instituições privadas. O Plano Nacional de Educação, proposto pelo executivo federal e em andamento no Congresso Nacional, amplia essas facilidades para o setor ao estender o FIES à pós-graduação.

4 O PROUNI foi criado em 2004, pela lei n. 11.096/2005, e tem como finalidade a concessão de bolsas de estudos integrais e parciais a estudantes de cursos de graduação e de cursos sequenciais de formação específica em instituições privadas de ensino superior. As instituições que aderem ao programa recebem isenção de tributos, representando, portanto, um financiamento indireto. 
a negociar ações na Bolsa de Valores (BOVESPA), inclusive com grupos que administram fundos internacionais.

Em síntese, os traços centrais da expansão do setor privado, no recorte histórico com o qual estamos trabalhando (pós-Reforma do Estado), são: o aprofundamento da diluição das fronteiras entre público e privado; a concentração institucional - com as incorporações de pequenas instituições por grandes organizações - e a financeirização e a internacionalização da educação superior. Tudo isso ocorre a partir de uma dinâmica ditada por grandes corporações de ensino, cujos acionistas auferem vultosos lucros, mas não dispensam o apelo ao fundo público, de forma direta ou indireta (Vale, 2011).

\section{A EXPANSÃO DO SETOR PÚBLICO E A CERTIFICAÇÃO EM MASSA}

Entre 1995 e 2010, as matrículas também tiveram um incremento no sistema público de educação superior da ordem de 134,5\%. Esse crescimento deveu-se principalmente à expansão da rede federal de educação superior, em especial no governo de Luiz Inácio Lula da Silva, por meio do programa REUNI.

O REUNI, criado pelo decreto presidencial n. 6.096, de 24 de abril de 2007, apresenta os seguintes objetivos: aumentar o número de estudantes de graduação nas universidades federais e de estudantes por professor em cada sala de aula da graduação (relação de dezoito alunos de graduação por professor em cursos presenciais); diversificar as modalidades dos cursos de graduação, por meio da flexibilização dos currículos, do uso do EaD, da criação dos cursos de curta duração, dos ciclos (básico e profissional) e/ou bacharelados interdisciplinares; incentivar a criação de um novo sistema de títulos; elevar a taxa de conclusão dos cursos de graduação para 90\% e estimular a mobilidade estudantil entre as instituições de ensino (públicas e/ou privadas).

As universidades federais aderiram a esse "termo de pactuação de metas", ou seja, um contrato de gestão com o MEC - instrumento-chave na Reforma de Bresser-Pereira -, pelo qual o governo prometia um acréscimo de recursos limitado a 20\% das despesas de custeio e pessoal, condicionado à capacidade orçamentária e operacional do referido ministério.

Com cinco anos de funcionamento, ainda se faz necessária uma análise mais acurada que cruze expansão discente/expansão docente e expansão discente/orçamento. Esse levantamento ainda não foi disponibilizado, todavia as investigações qualitativas já realizadas em algumas universidades ${ }^{5}$ autorizam-nos a aventar, como hipótese, as bases que de fato sustentam esse programa governamental de expansão da educação superior:

5 As universidades pesquisadas até o momento foram: Universidade Federal do Pará (UFPA); Universidade Federal do Maranhão (UFMA); Universidade Federal Fluminense (UFF); e Universidade Federal de Uberlândia (UFU). 
1) o mais-trabalho do professor, visto que a explosão do número de vagas discentes nas universidades federais tem ocorrido sem a correspondente ampliação das vagas docentes;

2) o aligeiramento do ensino, particularmente pela flexibilização de currículos e uso do $\mathrm{EaD}$, intensificando assim o processo de certificação em larga escala.

Tais hipóteses ganharam consistência positiva, a partir do final de maio de 2012, quando os docentes das instituições federais iniciaram uma greve, por tempo indeterminado, reivindicando a melhoria das condições de trabalho docente. Mais de cinquenta instituições de ensino superior federais paralisaram suas atividades com o propósito de auferir mudanças na carreira docente. Todavia, outras políticas governamentais para o setor, particularmente o programa REUNI, foram citadas criticamente em documentos e assembleias de docentes de todo o país, pela destruição que vem provocando na universidade pública. Entre os argumentos utilizados sobre o REUNI, merece registro a crítica feita ao aumento do número de estudantes sem o necessário incremento no número de professores e técnicos, o que tem intensificado sobremodo o trabalho docente, e o questionamento quanto aos recursos destinados para a construção da estrutura física, insuficientes para o atendimento da expansão em curso e para a qualidade das atividades acadêmicas.

\section{A EXPANSÃO DO EAD NO BRASIL}

Outra marca da expansão em curso no país refere-se ao uso do EaD, que vem sendo concebido como uma modalidade privilegiada para promover a democratização, a expansão do ensino e até para alavancar a transformação social via educação.

Nos primeiros anos do recorte histórico aqui considerado (1995), o número de matrículas no EaD era tão pequeno que sequer foi divulgado oficialmente. Os primeiros dados sobre o uso do $\mathrm{EaD}$ só passam a fazer parte das estatísticas oficiais brasileiras em 2000, constando o insignificante número de 1.682 matrículas, todas na rede pública. Como exposto no Gráfico 2, o EaD não parou de crescer desde então, chegando em 2010 a um total de 930.179 matrículas (Mancebo; Martins, 2012).

A oferta de vagas também cresceu exponencialmente, passando de pouco mais de seis mil em 2000, para 1,7 milhão em 2010, número praticamente igual ao de concluintes do ensino médio, que foi da ordem de 1,8 milhão em 2010.

Os dados apresentados justificam plenamente a afirmação de que tanto as instituições de ensino superior privadas quanto governos (especialmente o federal) investiram de forma intensa na ampliação de cursos a distância, de modo que o $\mathrm{EaD}$ representava somente $0,06 \%$ do total de matrículas em 2000 , percentual que salta para 14,58\% em 2010 (idem).

Cabe ainda destacar que, no processo de expansão do ensino superior a distância, as instituições públicas e privadas inserem-se de forma diferenciada ao longo dos anos.

A situação evidenciada no Gráfico 3 pode ser assim delineada: até o final do governo de Fernando Henrique Cardoso, em 2002, as instituições credenciadas 
Gráfico 2 - Evolução das matrículas a distância no ensino superior brasileiro (2000-2010)

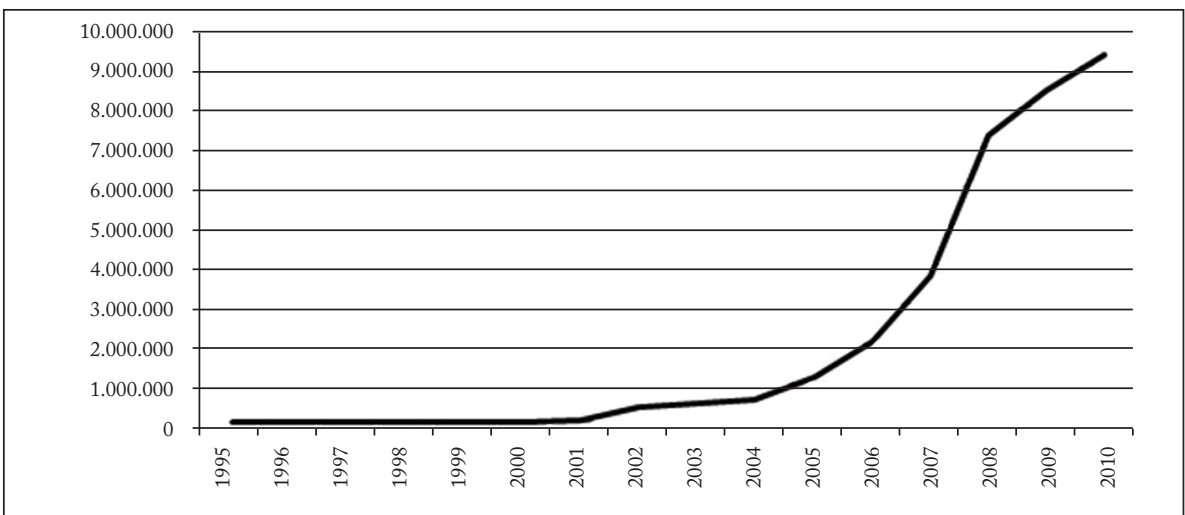

Fonte: Brasil; MEC; INEP (2011).

Elaboração das autoras.

Gráfico 3 - Evolução das matrículas dos cursos de graduação a distância no Brasil, por organização acadêmica (2000-2010)

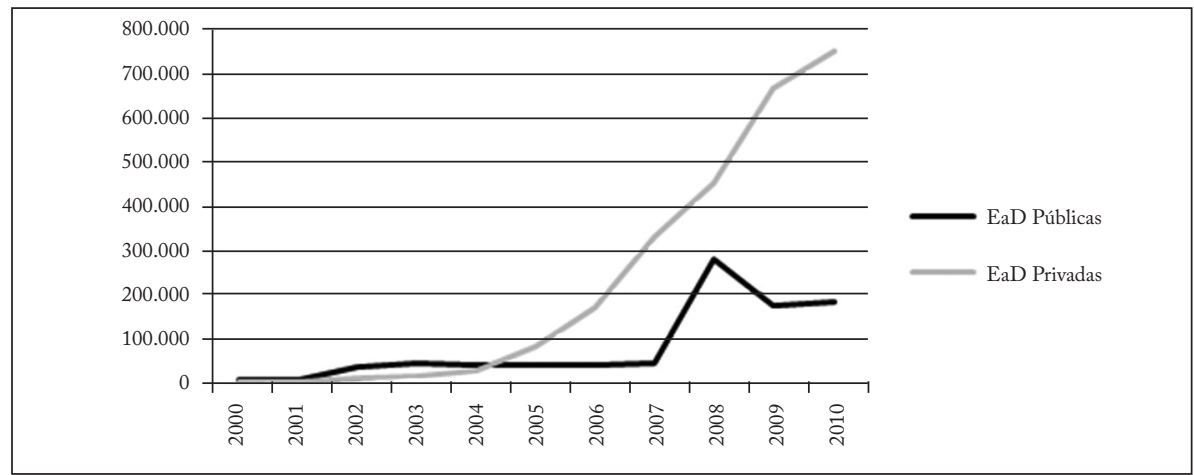

Fonte: Brasil; MEC; INEP (2011).

Elaboração das autoras.

pelo MEC para ofertar $\mathrm{EaD}$, em nível de graduação, eram pertencentes ao setor público. A partir dos anos 2002-2003, ocorreu um aumento crescente da participação do setor privado na oferta do $\mathrm{EaD}$, de modo que no ano de 2005 ocorre uma tendência de inversão dessa situação, com a iniciativa privada ultrapassando o número de matrículas, cursos e oferecimento de vagas em relação ao setor público. Essa tendência permanece, chegando-se, em 2010, ao seguinte quadro: do total de 930.179 matrículas no $\mathrm{EaD}$, somente 181.602 (ou 19,52\%) encontravam-se nas instituições públicas, enquanto 748.577 (ou 80,48\%) eram da rede privada. 
Esse quadro geral relativo ao aumento do $\mathrm{EaD}$ no país decorre, entre outros fatores, da política formulada pelo Estado brasileiro para promover a expansão do ensino superior, conforme previsões contidas nos seus planos educacionais, e da facilidade para credenciar instituições e cursos frente a um marco regulatório pouco consistente para o EaD.

No caso específico do setor privado, o argumento forte para sua inserção na oferta do $\mathrm{EaD}$ refere-se à exaustão da oferta de cursos presenciais (que haviam se expandido de forma extraordinária nos últimos anos do século XX), o que remeteu a fração da burguesia brasileira que detém essa fatia de mercado à busca de novos espaços para a expansão e realização de seus lucros.

Deve-se destacar, ademais, que, apesar do aumento da oferta de EaD na rede privada ser superior ao da rede pública, essa modalidade de ensino também se amplia neste último setor, particularmente por meio da Universidade Aberta do Brasil (UAB), criada pelo decreto n. 5.800, de 8 de junho de 2006.

A UAB é uma fundação de direito privado que se apresenta como "um sistema voltado para o desenvolvimento da modalidade de educação a distância, com a finalidade de expandir e interiorizar a oferta de cursos e programas de educação superior no país" (Brasil, 2006). Ela foi idealizada a partir do Fórum das Estatais pela Educação, ${ }^{6}$ em 2005, com o objetivo prioritário de capacitar os professores da educação básica e buscar interiorizar a oferta de cursos e programas de educação superior, atuando com prioridade na formação e capacitação inicial e continuada de professores para a educação básica com a utilização de metodologias do $\mathrm{EaD}$. A proposta oficial do fórum era fortalecer as universidades públicas e, ao mesmo tempo, atender às necessidades das empresas, enfatizando o papel da educação no desenvolvimento econômico brasileiro (Fórum das Estatais pela Educação, 2009).

$A$ UAB não cria uma nova instituição de ensino paralelo às IES, mas articula as IES já existentes, mediante convênios e parceiras que envolvem as esferas de governo (União, estados e municípios) e instituições federais e estaduais de ensino superior, contando com acompanhamento/avaliação da chamada Nova CAPES (Barreto, 2008, p. 928). Concretamente, o funcionamento da UAB ocorre da seguinte maneira: os municípios que desejam participar do projeto devem montar um polo presencial, com laboratórios e biblioteca para os alunos, e demais infraestruturas aos tutores presenciais que ficam à disposição dos alunos. Os cursos e o material didático-pedagógico são de responsabilidade das instituições de todo o país. O MEC abre as inscrições (editais) às universidades públicas para que estas se integrem ao programa, e as universidades elaboram um projeto completo de oferta de curso superior com os polos pré-selecionados entre as cidades brasileiras. Cada polo pode receber cursos de uma ou várias IES, conforme as necessidades de cada região e da particularidade de cada instituição universitária.

6 O Fórum das Estatais pela Educação tem a coordenação geral do ministro-chefe da Casa Civil, com a coordenação executiva do ministro da Educação e a participação efetiva e estratégica das empresas estatais brasileiras. Disponível em: <http://portal.mec. gov.br/arquivos/pdf/texto.pdf>. Acesso em: 30 mar. 2009. 
Assim concebida, a UAB possui um grande potencial para a oferta de vagas no ensino superior, porque não considera os mesmos padrões de investimento das IES. Todavia, ao assim fazê-lo, muda estruturalmente o perfil da universidade, os rumos de sua valorização e prestígio, por meio do sucateamento deste nível de ensino. Em acréscimo, contribui para a intensificação do trabalho docente e a dissociação entre "ensino-pesquisa-extensão". Conforme o Sindicato Nacional dos Docentes das Instituições de Ensino Superior (ANDES-SN, 2007), a UAB representa uma das maiores ameaças à universidade brasileira, além de levar ao descrédito o próprio sentido do ensino superior a distância, que funciona com boa adequação em outros países, pois no Brasil a UAB não representaria nem mesmo uma universidade em sentido pleno, uma vez que a pesquisa e a extensão inexistem.

Diante do exposto, pode-se afirmar que a UAB carrega indevidamente a denominação de universidade. No máximo, é mais um programa de educação que se une às IES nos três níveis da federação. Ademais, não possui um corpo de funcionários próprios, nem mesmo infraestrutura adequada e própria para garantir o pleno desenvolvimento da expansão a que se propõe. Seu corpo docente trabalha por intermédio de bolsas concedidas a professores e tutores, que, em muitos casos, nem a qualificação necessária possuem em termos de titulação e produção acadêmica.

Criada como uma experiência-piloto, rapidamente se institucionalizou e integrou-se definitivamente ao ensino superior brasileiro, de forma apressada, sem nenhum debate qualificado com a comunidade acadêmica. Apresenta inequívoco crescimento, estando presente em praticamente todos os estados do Brasil. Entre os cursos ofertados destacam-se os cursos de licenciaturas e pedagogia, imprimindo uma marca muito clara para a experiência: a formação de professores da educação básica, com um ensino que não tem qualquer critério ou sistema de avaliação institucional nem padrões de mensuração da qualidade do processo de ensino-aprendizagem (Mancebo; Martins, 2012).

Orientada por um discurso de democratização do acesso para uma parcela da população historicamente excluída da educação, a expansão indiscriminada dos cursos na modalidade $\mathrm{EaD}$ acarreta vários problemas para a formação e para os que nela trabalham, problemas estes que merecem ser debatidos (Silva Júnior; Martins, 2013b).

O primeiro deles é a ausência de infraestrutura adequada. Como sabido, a implantação de cursos a distância exige altos investimentos em seu estágio inicial; nos estágios subsequentes, com o avanço do projeto, é preciso considerar novos incrementos em manutenção e atualização tecnológica e a expansão das funções e qualificações docentes. Os municípios parceiros das IES públicas são os responsáveis pela disponibilidade física, bibliotecas, laboratórios, serviços de comunicação e pagamento de coordenadores locais. No entanto, conforme Alonso (2010), muitos municípios não dispõem de condições para organizar os polos com a qualidade necessária, de modo que, muito provavelmente, os estudantes também não terão acesso fácil a boas bibliotecas nem ao necessário contato pessoal com outros estudantes e professores da mesma área e, muito menos, com estudantes e professores de áreas diferentes, o que normalmente ocorre nas universidades (Helene, 2012). 
Um aspecto normalmente negligenciado, mas que interfere sobremodo no aprendizado, é que o $\mathrm{EaD}$ pressupõe que todo o processo (ou boa parte dele) ocorra, majoritariamente, na casa do aluno. Ora, "o ambiente de moradia não é, em geral, um bom ambiente de estudo, em especial para jovens das camadas menos favorecidas, para os quais uma moradia isolada e silenciosa é algo simplesmente inexistente" (idem, p. 6). Assim, em resposta aos que proclamam o uso do EaD como forma de democratizar o acesso a uma parcela da população historicamente excluída, deve-se contrapor que o $\mathrm{EaD}$ não resolverá o problema da exclusão, apenas mudará a forma pela qual ela ocorre.

Outro problema que merece consideração no $\mathrm{EaD}$ é o trabalho do docente. Ele é substancialmente desenvolvido por tutores que não desfrutam do mesmo reconhecimento e tratamento legal dado aos professores em geral, não dispondo sequer de vínculo empregatício, muito embora desenvolvam atividades tipicamente docentes. A resolução n. 8, de 30 de abril de 2010, do MEC, é exemplar nesse aspecto, ao destacar que os tutores devem trabalhar mediante o recebimento de bolsas, um tipo de contratação que evita a criação de vínculo empregatício e a garantia de benefícios e direitos comuns aos trabalhadores, como carreira docente, décimo terceiro salário, férias, bem como a contagem de tempo para a composição da base de cálculo da aposentadoria. Na expressão de Segenreich (2009, p. 219), criou-se "uma subclasse docente, apesar da importância do tutor no processo ensino-aprendizagem dessa modalidade de ensino". Configura-se, assim, um processo de precarização e flexibilização das relações de trabalho, no caso da UAB, dentro da própria universidade pública. Paralelamente, as empresas privadas que atuam no mercado educacional desse setor passam a dispor de significativas oportunidades adicionais para continuarem a fazer da educação um negócio lucrativo, barateando o custo da mão de obra por meio do uso abusivo da prestação de serviços (Mancebo; Martins, 2012).

Além disso, o trabalho docente no $\mathrm{EaD}$ é fragmentado e em série. Uma parte das tarefas educativas é realizada pelos professores conteudistas e coordenadores, responsáveis pela elaboração e pelo planejamento dos cursos. Outra, bem diversa, é feita pelos tutores, que acompanham sua execução em um ambiente virtual com inúmeros alunos. Para estes, todas as atividades são padronizadas e parceladas, sem oferecer margens ao trabalho docente criativo e inovador, o que faz com que a autonomia docente seja drasticamente diminuída.

$\mathrm{Na}$ realidade, a ação do tutor restringe-se a preparar o ambiente, ele deve ser um facilitador do aprendizado de competências, um animador do processo que deve estimular nos alunos a autonomia e a capacidade de aprender a aprender. O que se exige dos tutores são características peculiares, como a capacidade de seduzir, impressionar, despertar simpatia, entusiasmar e motivar o aluno, com objetivo de que este não crie resistência ao estudo, nem desista do curso (Silva Júnior; Martins, 2013a).

Por fim, cabe perguntar-nos como um uso tão pretensioso das tecnologias da informação e comunicação (TIC) tem ocorrido. Primeiramente, conforme argutas análises de Barreto (2003, 2004, 2008), as TIC têm sido reduzidas a estratégias de $\mathrm{EaD}$, que, em vez de fortalecer as instâncias universitárias de formação, promovem um modelo de substituição tecnológica, que representa uma certificação em larga 
escala; quebram "a unidade constituída por ensino-aprendizagem, em nome de uma suposta valorização do segundo elemento do par, apagando o território do ensino, do exercício cotidiano do trabalho docente"(Barreto, 2003, p. 282); abortam a pesquisa stricto sensu e fazem o elogio de uma atitude investigativa, que remete a um inegável empobrecimento conceitual, na medida em que reconhece a prática apartada da construção teórica.

A justificativa para a acelerada expansão do $\mathrm{EaD}$ traduz uma crença quase que milagrosa nos poderes das TIC para a resolução de problemas os mais diversos. Uma crença que nos atravessa mais intensamente a partir da segunda metade do século XX e que remete a um "discurso salvador sobre a promessa de concórdia universal, de democratização descentralizada, de justiça social e de prosperidade geral" (Mattelart, 2002, p. 31), mediante o uso cada vez maior da técnica tomada, assim, como um dispositivo neutro. A hipertrofia da dimensão técnica, em diversos campos, inclusive no educacional, traduz uma crença no determinismo tecnológico, apresentando a tecnologia descontextualizada do meio social que a circunda.

Entendemos, ao contrário, que a tecnologia não é neutra, mas determinada pela ação dos agentes envolvidos. No capitalismo, é impulsionada pelo desejo do capitalista em gerar mais-valia relativa por meio do trabalho humano dinamizado pela tecnologia. O fato de a tecnologia ser usada para intensificar o trabalho humano e também desvalorizá-lo não se deve à máquina em si mesma, mas ao seu uso pelo capitalista (Sousa; Gomes; Hayashi, 2009, p. 11).

Admitir que o mundo capitalista esteja mudando ou que já tenha mudado e sido superado em virtude de uma "revolução científico-tecnológica", em cujo centro estariam as TIC, significa assumir uma posição determinista e tecnicista e pressupor que as TIC podem ser pensadas fora das relações que constituem o contexto da sua produção (Barreto, 2010). Do mesmo modo, tratar as relações entre as TIC e o EaD como inevitáveis e desejáveis para um novo paradigma educacional, porque apresentam a potencialidade de solucionar os problemas atuais, é simplificar a questão, desconsiderando, entre outros aspectos, que essa solução foi imposta de modo vertical, sem levar em conta as condições de trabalho nas escolas, o duro cotidiano enfrentado por alunos e professores, a experiência que esses personagens acumularam ao longo de sua vida pessoal e coletivamente (Mancebo; Martins, 2012).

Em contrapartida, também é preciso não simplificar as muitas conexões que o ufanismo nacional em relação às TIC e ao $\mathrm{EaD}$ apresentam. Em particular, deve-se considerar: (1) as recomendações e condicionalidades estabelecidas pelos organismos internacionais - como a farta literatura do Banco Mundial indica para os países periféricos (do Sul), no que tange à incorporação educacional das TIC, mas também os relatórios da UNESCO e a Organização para a Cooperação e Desenvolvimento Econômico (OCDE); (2) as traduções e adaptações que essas condicionalidades enfrentam quando se concretizam em formulações locais; (3) os interesses de uma fração da burguesia local (brasileira), que possui sólidos negócios na área educacional, que anteveem no uso das tecnologias na educação possibilidades férteis de minimização do trabalho humano, ampliação do número de alunos e crescimento de suas margens de lucro. 


\section{A EXPANSÃO DA PÓS-GRADUAÇÃO E O EMPRESARIAMENTO DO CONHECIMENTO}

O quarto eixo da expansão em curso refere-se ao crescimento da pós-graduação e ao conhecimento que aí é gerado.

No Brasil, o lugar precípuo de produção de conhecimento e da decorrente centralidade da pesquisa é a pós-graduação, que, em 2010, compreendia 2.840 programas (em sua grande maioria localizada na rede pública), com cursos de mestrado, doutorado e mestrado profissional, absorvendo 60.039 docentes (entre professores permanentes, colaboradores e visitantes) e uma população de 173.408 estudantes. $^{7}$

As políticas públicas de ciência e tecnologia começaram a se estruturar como tal, no Brasil, na década de 1950, fundamentalmente por meio das grandes agências de fomento à pesquisa, ainda hoje as mesmas (CNPq e CAPES). Assim, desde sua origem, as políticas de Estado e as instituições de educação superior exercem seus efeitos diretamente sobre o sistema de pós-graduação, os sujeitos individuais (pesquisadores), os atores institucionais (programas de pós-graduação) e sobre o campo da produção do conhecimento científico e tecnológico.

Um curso de pós-graduação no Brasil, para ter validade nacional, deve ser recomendado pela CAPES. Posteriormente, será avaliado anualmente e conceituado de três em três anos, o que cria um sistema de controle e regulação de cada um dos cursos e do espaço social que integram. Em contrapartida, o que é de extrema importância, a mesma agência que avalia (CAPES) define parte substancial do financiamento dos diversos cursos, detendo, assim, uma margem de poder bastante ampla no que diz respeito à indução (para onde deseja que o crescimento do sistema ocorra) e ao controle do seu cumprimento.

Sobre a indução, em termos gerais, pode-se dizer que, em princípio, o sistema de pós-graduação brasileiro procurou formar professores no ensino superior. A partir de 1982 (II Plano Nacional de Pós-Graduação - PNPG/1982-1985), a principal preocupação passou a ser com o desempenho, a qualidade, e, consequentemente, a avaliação do sistema ganha densidade e investimentos. Após o III PNPG (1986-1989), a indução recai para o desenvolvimento de pesquisas nas universidades. Mais recentemente, desde o V PNPG (2005-2010), ocorre uma indução mais forte e definida, que direciona o sistema de pós-graduação para a produção de tecnologia e inovação e, consequentemente, para o estabelecimento de laços mais fortes com as empresas, o que ganhou contornos mais nítidos com a promulgação da lei n. 11.079, de 30 de dezembro de 2004, ${ }^{8}$ e com o decreto n. 6.260, de 20 de novembro de 2007, conhecido como Lei de Inovação Tecnológica. ${ }^{9}$

7 Os dados foram obtidos em: Brasil. MEC. Coordenação de Aperfeiçoamento de Pessoal de Nível Superior. Brasília, 2011. Disponível em: <http://www.capes.gov.br/ sobre-a-capes/estatisticas>. Acesso em: 20 jun. 2011.

8 A lei n. 11.079, de 30 de dezembro de 2004, institui normas gerais para licitação e contratação de parceria público-privada no âmbito da administração pública.

9 A Lei de Inovação Tecnológica viabiliza a transferência de tecnologia das universidades e centros de pesquisa para as empresas, prevendo a incubação de empresas no 
Para os objetivos deste texto, interessa-nos destacar dois aspectos. O primeiro refere-se à indução para a produção de conhecimento na pós-graduação. Considerando que os recursos para pesquisa não são suficientes para toda a demanda do país, ao mesmo tempo em que sua distribuição ocorre a partir da avaliação da produtividade do pesquisador ou da equipe de investigação ou ainda do programa de pós-graduação, não é difícil chegar-se à conclusão de que ocorre um aumento significativo na competição por recursos e uma encarniçada corrida pela produtividade (Mancebo, 2013). A alta produtividade é o resultado inevitável, que se transforma em política de Estado, independente dos governos, torna-se quase autoadministrada e cria um efeito perturbador sobre a atividade científica, especialmente com a crescente sofisticação dos instrumentos de avaliação.

Em segundo lugar, a indução que mais agressivamente vem ocorrendo para que as universidades, em especial a pós-graduação, vinculem-se às empresas e venham a contribuir para o desenvolvimento do país também merece nossa atenção. Neste caso, os documentos oficiais fazem uso de uma fórmula ideológica, segundo a qual a pesquisa científica e tecnológica é base para a inovação e para a formação de recursos humanos qualificados, com impactos significativos no crescimento e na geração de riquezas. Conforme pesquisador da área (Dagnino, 2012), a cadeia pesquisa-inovação nas empresas-crescimento - é ideológica, porque não há evidência empírica que justifique que "a inovação das empresas [seja] capaz de fazer o país melhorar seus índices sociais" e de assegurar o crescimento. Para Dagnino (idem): "no mundo inteiro o que se vem observando é o contrário".

$\mathrm{Na}$ realidade, a produção de ciência, tecnologia e inovações tecnológicas é imprescindível para que o capitalismo possa renovar-se e ampliar sua margem lucro, a partir da base industrial consolidada (Pochmann, 2008), e as universidades brasileiras têm sido chamadas a desempenhar um papel destacado no processo de produção de valor, fazendo jus às análises de Trein e Rodrigues (2011, p. 775), quando afirmam:

No modo de produção capitalista, há um empuxo irresistível na conversão de todos os objetos e atividades úteis ao homem [...] em mercadoria. O que, na prática, significa que todos os objetos (ou atividades) tenderão a ser produzidos (ou desempenhadas) para serem mercadejados. [...] Em outras palavras, em nossa sociedade, as coisas, as pessoas, e o conhecimento científico sofrem um empuxo à mercantilização, ou seja, a subsunção de seu valor de uso ao valor de troca. O conhecimento científico, nessa perspectiva, só tem valor se tem valor de troca, se é conversível em outra mercadoria, se pode ser mercantilizado, enfim.

espaço público, a possibilidade de compartilhamento de infraestrutura, equipamentos e recursos humanos e o afastamento de pesquisadores das universidades públicas, para tentar transformar seus inventos em negócios, além de autorizar o aporte de recursos orçamentários diretamente à empresa, no âmbito de um projeto de inovação. 


\section{CONSIDERAÇÕES FINAIS}

Este texto pretendeu apresentar as principais tendências da expansão da educação superior no Brasil, no período compreendido entre 1995 e 2010, com a discussão de quatro grandes linhas de análise. Primeiramente, expôs o progressivo quadro de privatização do sistema de educação brasileiro, no que se refere tanto ao crescimento ininterrupto das instituições privado-mercantis quanto à mercantilização das IES públicas. Apresentou as ações do governo federal expandindo vagas, matrículas e cursos nas instituições federais de ensino superior, analisando particularmente o programa REUNI, que dá curso à expansão por meio de contratos de gestão, que certificam em massa, mas à custa da flexibilização e rebaixamento dos cursos e da intensificação do trabalho dos professores. Em seguida, expusemos o vertiginoso quadro de expansão de cursos, vagas e matrículas de $\mathrm{EaD}$ que, em vez de fortalecer as instâncias universitárias de formação docente pela incorporação das TIC, promove um modelo de substituição tecnológica. Na última parte do texto, analisamos a expansão da pós-graduação com redefinição de seus rumos no sentido do empresariamento do conhecimento.

Em todos esses campos da educação superior brasileira, foram induzidas alterações substantivas no trabalho docente, no que tange tanto à formação quanto à produção de conhecimento, sob a regência de um ideário que apela à economia de mercado, minimiza as áreas de atuação do Estado, racionaliza os gastos públicos com base em um sistema de parceria entre Estado e mercado e suprime diversos direitos e conquistas sociais transmutados em serviços, regidos por um intenso processo de mercantilização. Essas mudanças fazem parte do movimento de reforma educacional - ou contrarreforma da educação superior, como já denominado por diversos autores críticos. Em outros termos, trata-se da necessidade histórica do sistema capitalista de avançar seu domínio sobre todos os campos da reprodução política e social, que, no nosso caso, impõe a redução do caráter público da educação a níveis cada vez mais insignificantes, posto o caráter semiprivatizado do Estado.

No retrospecto realizado verificou-se, por fim, um argumento que é reiterado em todas as situações abordadas e que necessita, portanto, de resposta. Segundo ele, há uma relação positiva entre educação e desenvolvimento, daí todo o esforço para a expansão do sistema de educação superior. Esse argumento, que advém nos anos 1950, com as teorias do capital humano, e que já foi sobejamente contestado por diversos autores no campo crítico, permanece de pé e é, até hoje, dominante, quando governantes e mídia, sob a batuta do capital, advogam mudanças, reformas e, no caso aqui em análise, a expansão de sistemas de ensino. Cabe retomar arguta análise de Frigotto, Ciavatta e Ramos (2009, p. 1.316) sobre a relação educação, educação profissional e desenvolvimento. Para esses autores:

Trata-se de uma relação que mantém um conteúdo colonizador, de subserviência e de alienação. Cabe ressaltar que tanto a situação da desigualdade entre regiões (Norte/Sul) ou entre países centrais e periféricos e semiperiféricos ou entre grupos sociais no interior de cada país não se explica, primeira e fundamentalmente, pela educação ou formação profissional [como reiteradamente 
nos querem fazer acreditar], mas pelas relações de poder e de força historicamente construídas.

É, pois, fundamental que se tenha claro que o caminho percorrido na relação entre educação e desenvolvimento não nos ajuda a entender o processo histórico da produção da desigualdade entre nações e no interior delas, não nos ajuda a compreender o atual processo de expansão da educação superior brasileira, bem como não nos auxilia a construir outra forma de expansão montada em outra equação na qual a formação e o conhecimento possam ser, de fato, socialmente úteis.

Harvey (2011, p. 11) inicia seu último livro enunciando que "se conseguirmos compreender melhor as perturbações e a destruição a que todos estamos expostos presentemente, talvez possamos começar a saber o que fazer”. No nosso caso, trata-se de compreender os significados (e sentidos) da expansão que se está a promover na educação superior, seus impactos na formação e produção do conhecimento, em uma economia mundializada, que mercantiliza, por seu turno, todas as dimensões da vida. O que fazer diante desse quadro permanece em aberto, daria vazão a outro texto, a ser escrito, com certeza, por um coletivo muito mais amplo.

\section{REFERÊNCIAS}

Alonso, K. M. A expansão do ensino superior no Brasil e a EaD: dinâmicas e lugares. Educação Ẽ Sociedade, Campinas: CEDES, v. 31, n. 113, p. 1.319-1.335, dez. 2010.

Andes-SN - Sindicato Nacional dos Docentes das Instituições de Ensino Superior. A Universidade Aberta do Brasil: faz-se necessário denunciar o engodo. Brasília, DF, 2007. Disponível em: <www.andes.org.br/univ_nova_engodo.html>. Acesso em: 8 out. 2011.

Barreto, R. G. Tecnologias na formação de professores: o discurso do MEC. Educação e Pesquisa, São Paulo: USP, v. 29, n. 2, p. 271-286, jul./dez. 2003.

Tecnologia e educação: trabalho e formação docente. Educação E̊ Sociedade, Campinas: CEDES, v. 25, n. 89, p. 1.181-1.201, set./dez. 2004.

As tecnologias na política nacional de formação de professores a distância: entre a expansão e a redução. Educação E̋ Sociedade, Campinas: CEDES, v. 29, n. 104 Especial, p. 919-937, out. 2008.

. Formação de professores a distância como estratégia de expansão do ensino superior. Educação E̋ Sociedade, Campinas: CEDES, v. 31, n. 113, p. 1.299-1.318, out./dez. 2010.

Brasil. Decreto n. 5.800, de 8 de junho de 2006. Dispõe sobre o sistema Universidade Aberta do Brasil - UAB. Diário Oficial [da] República Federativa do Brasil. Brasília, DF, 2006. Disponível em: <http://www.planalto.gov.br/ccivil_03/_Ato2004-2006/2006/ Decreto/D5800.htm>. Acesso em: 10 maio 2011.

MEC. INEP. Sinopses estatísticas do Censo da Educação Superior: 1995 a 2011. Brasília: MEC, 2011. Disponível em: <http://www.inep.gov.br/superior/censosuperior/ sinopse/default.asp>. Acesso em: 25 jan. 2012. 
Dagnino, R. Entidades se unem em defesa de recursos para CT\&I. Jornal da Ciência, Natal: ANPEPP, n. 4.465, 28 mar. 2012.

Fórum das Estatais pela Educação. Diálogo para a cidadania e inclusão. Brasília, DF: 2004. Disponível em: <http://portal.mec.gov.br/arquivos/pdf/texto.pdf>. Acesso em: 30 mar. 2009.

Frigoto, G.; Ciavatta, M.; Ramos, M. Vocational education and development. In: UNESCO-UNEVOC (Orgs.). International handbook of education for changing world of work. 1. ed. Bonm, Germany: UNESCO; UNEVOC, 2009. v. 3, p. 1.307-1.319.

Harvey, D. O enigma do capital e as crises do capitalismo. Lisboa: Bizâncio, 2011.

Helene, O. A privatização do ensino superior. Brasil de Fato, São Paulo: Sociedade Editorial Brasil de Fato, n. 441, 16 ago. 2011. Disponível em: <http://www.brasildefato. com.br/node/7136>. Acesso em: 1 jun. 2012.

. Ensino à distância não é uma solução, e sim outro problema a ser superado. Revista da FEPESP, São Paulo, 22 maio 2012. Disponível em: <http://www.fepesp. org.br/revista_corpo2.asp?id=2098\&moda=013\&contexto=\&area=>. Acesso em: 6 jun. 2012.

Mancebo, D. Trabalho docente e produção de conhecimento. Psicologia E Sociedade, Belo Horizonte: ABPS, v. 25, p. 519-526, 2013.

.; Martins, T.B. Expansão do ensino a distância: pressupostos para sua análise e marcos regulatórios. In: Mancebo, D.; Silva Júnior, J. R. (Orgs.). Trabalho docente e expansão da educação superior brasileira. Rio de Janeiro: EDUERJ, 2012. p. 117-146.

Mattelart, A. História da sociedade da informação. São Paulo: Loyola, 2002.

Paulani, L. Brasil delivery. São Paulo: Boitempo, 2008.

Pochmann, M. Riqueza concentrada e trabalho em excesso. Folha de São Paulo, São Paulo, 21 mar. 2008, p. 3B.

Segenreich, S. C. D. ProUni e UAB como estratégias de EaD na expansão do ensino superior. Pro-Posiçôes, Campinas: UNICAMP, v. 20, n. 2 (59), p. 205-222, maio/ago. 2009.

SGUISSARD, V.Modelo de expansão da educação superior no Brasil: predomínio privado/ mercantil e desafios para a regulação e a formação universitária. Educação E̊ Sociedade, Campinas:CEDES,v.29, n. 105, p.991-1022, dez.2008.Disponível em: <http://www.scielo. br/scielo.php?script=sci_arttext\&pid= S010173302008000400004\&lng=pt\&nrm=iso > Acesso em: 22 set. 2011.

Silva Júnior, J. R.; Martins, T. B. Formação e certificação em massa e abordagens do multiculturalismo e das competências na educação a distância: implicações ao trabalho docente. Revista HISTEDBR Online, v. 13, p. 238-251, 2013a.

;____. Expansão do ensino superior: trabalho docente na Universidade Aberta do Brasil. In: Almeida, M. L. P.; CATANi, A. M. (Orgs.). Educação superior na América Latina: políticas, impasses e possibilidades. Campinas: Mercado de Letras, p. 239-266, 2013b. 
Siteal - Sistema de Información de Tendencias Educativas en América Latina. Cobertura relativa de la educación pública y privada en América Latina. Dato Destacado, Buenos Aires, n. 23, sep. 2011.

Sousa, C. M.; Gomes, G. F.; Hayashi, M. C. P. I. A concepção da tecnologia em O Capital de Marx. In: Simpósio Nacional de Tecnologia e Sociedade: desafios para a transformação social, 3., 2009, Curitiba. Anais... Curitiba: Universidade Tecnológica do Paraná, 10-13 nov. 2009.

Trein, E.; Rodrigues, J. O mal-estar na academia: produtivismo científico, o fetichismo do conhecimento-mercadoria. Revista Brasileira de Educaşão, Rio de Janeiro: ANPEd; Campinas: Autores Associados, v. 16, n. 48, p. 769-819, set./dez. 2011.

VALE, A. A. As faculdades privadas não fazem pesquisa porque não querem jogar dinheiro fora: a trajetória da Estácio de Sá, da filantropia ao mercado financeiro. 2011. Tese (Doutorado em Políticas Públicas e Formação Humana) - Universidade Estadual do Rio de Janeiro, Rio de Janeiro, 2011.

\section{SOBRE AS AUTORAS}

Deise Mancebo é doutora em educação pela Pontifícia Universidade Católica de São Paulo (PUC-SP). Professora titular da Universidade do Estado do Rio de Janeiro (UERJ).

E-mail: deise.mancebo@gmail.com

Andréa Araujo do Vale é doutora em políticas públicas e formação humana pela Universidade do Estado do Rio de Janeiro (UERJ). Professora adjunta da Universidade Federal Fluminense (UFF).

E-mail: andreaavale@ig.com.br

TÂnia Barbosa Martins é doutora em educação pela Universidade Federal de São Carlos (UFSCar). Professora da Universidade Metodista de Piracicaba (UNIMEP).

E-mail: taniabmartins@yahoo.com.br 